\title{
The Duel of Honor: Screening For Unobservable Social Capital
}

Douglas W. Allen and Clyde G. Reed, Simon Fraser University

The duel of honor was a highly ritualized violent activity practiced (mostly) by aristocrats from about 1500 to 1900 . The duel of honor was held in private, was attended by seconds and other members of society, was illegal, and often resulted from trivial incidents. Duels were fought according to strict codes, their lethality fell over time, and certain members of society were not allowed to duel. We argue dueling functioned as a screen for unobservable investments in social capital. Social capital was used during this period to support political transactions in an age when high civil service appointments were made through patronage. The screening hypothesis explains the puzzling features of the duel of honor, its rise and fall over time and locations, and the differences between European and American duels.

In a state of highly polished society, an affront is held to be a serious injury. It must, therefore, be resented, or rather a duel must be fought upon it; as men have agreed to banish from their society one who puts up with an affront without fighting a duel.

- Samuel Johnson, quoted in James Boswell

Thanks to James Amegashi, David Andolfatto, Yoram Barzel, Cliff Bekar, Phil Curry, Greg Dow, Bob Ellickson, Chris Hall, Dean Lueck, Christoph Lülfesmann, Eric Posner, Tom Ross, Wing Suen, participants at the 2003 Cliometrics meeting, the Yale Law School Law and Economics seminar, and the referee for their slashing remarks and penetrating comments.

Send correspondence to: Douglas W. Allen, Department of Economics, Simon Fraser University, Burnaby, BC V5A 1S6. Phone: (604) 291-3445; Fax: (604) 291-5944.

American Law and Economics Review doi:10.1093/aler/ahj006

(C) The Author 2006. Published by Oxford University Press on behalf of the American Law and Economics Association. All rights reserved. For permissions, please e-mail: journals.permissions@oxfordjournals.org 


\section{Introduction}

In 1829 the Duke of Wellington, much to the chagrin of the antiCatholic Earl of Winchilsea, helped bring about the passage of the Roman Catholic Relief Bill. When the duke later became the patron of King's College, London, the earl took the opportunity in writing to suggest the duke was acting under the "cloak of some outward show of zeal for the Protestant religion" in order that he might bring about the "introduction of Popery into every department of the state." ${ }^{11}$ When the letter reached the press, the duke sought a public withdrawal and apology, and when none was forthcoming the duke demanded "satisfaction" in the form of a duel. Winchilsea granted the duel, stating that "the satisfaction which your Grace has demanded, it is of course impossible for me to decline." A pistol duel took place the next morning, with both parties missing, and a letter of apology was produced by the earl immediately afterward.

Several aspects of this story seem incredible: the grounds for the duel are trivial, the response to settle a "point of honor" with pistols is an overkill, and the earl's reply of "no choice but to accept" is unbelievable. Furthermore, the immediate production of a prepared apology makes one wonder why well-established lives were put on the line. As unlikely as these facts appear, they characterized most duels of honor.

\subsection{A Brief History of Dueling}

The "duel of honor" began c.1500, peaked in the 1600s, and lasted in some places until the First World War. ${ }^{2}$ The duel of honor had several characteristics: the causes of the duel were often trivial, the "guilty" party

1. See Baldick (1965, pp. 104-6) for a discussion of the whole affair.

2. Dueling has a long history, much of which is only peripheral to the central elements of our analysis (see Baldick, 1965, for a detailed history). Dueling began around the turn of the first millennium and took the form of the "judicial duel" or "trial by combat." These duels decided matters of justice with the belief that God would prevail for the righteous. The loser of such a duel, if not killed, would often suffer additional consequences, such as the removal of a hand or hanging, depending on the crime. The other form of dueling in the middle ages was the "duel of chivalry" between knights and other nobles, conducted as sport. These duels often took place on horseback and used lances and spears as weapons. The fading of feudalism marked the end of the chivalrous duel, with the last English example in 1492 and the last French example in 1547. 
was not necessarily the loser of the duel, the outcome was irrelevant in terms of social standing, after a duel reconciliation was common, and duels were regulated by strict sets of rules; and duel lethality fell over time. ${ }^{3}$ Though dueling was generally illegal and though the punishments were often severe if parties were convicted, duelists were seldom brought to court, rarely convicted, and if convicted likely pardoned. Penalties for dueling among the elites usually occured only if there was evidence the duel was not fair or did not follow a conventional code of conduct (Kiernan, 1988, p. 102). In contrast, commoners caught dueling would be charged with attempted murder.

Weapons in the duel of honor were restricted to a subset of lethal weapons. Early duels were fought with a rapier and dagger. The rapier was a heavy, inflexible straight sword used for stabbing, while the dagger was used to parry thrusts from the opponent. Soon all defensive weapons such as shields, helmets, and armor were eliminated, and even the dagger was dropped as an allowable weapon. Eventually, the rapier was replaced with the lighter, more flexible épée, and duels became much quicker affairs. In various regions the épée remained the weapon of choice, but in the eighteenth century the saber was introduced. This was a slashing weapon and, although it could cause much damage, was generally not as lethal as the épée. Finally, dueling with pistols was introduced in the late eighteenth century and replaced most fencing duels.

Duels of honor were a European invention. Starting in Italy, dueling quickly spread to France, what is now Germany, and the rest of Europe. Dueling was brought to the Americas and was conducted in Canada, Mexico, and the United States. Dueling ended first in the northern European countries by the late eighteenth century. It ended in England in the first half of the nineteenth century, ended in the U.S. by the American Civil War, and lasted in France and Germany until the First World War. Dueling was the sole domain of the ruling aristocratic class until the late nineteenth century, whereupon upper-middle-class professionals also began to duel.

3. Duels were fought over an insult, a slap to the face, a slur on reputation, "coolness of manner," or, most serious of all, an accusation of lying. "The accusation of lying was ... the essential act which set in motion the duel procedure" (Billacois, 1990, p. 9). 


\subsection{Dueling Literature}

Although economists and economic historians have ignored the exotic institution of dueling, it has attracted attention among social historians and legal scholars. According to social historians, dueling is considered a manifestation of inherent male violence (see, e.g., Kiernan, 1988, McAleer 1994). In addition, this literature often considers dueling a substitute for war, in that it provides a release for aggression. According to Nye (1998), "[T]he duel was still, as it had always been, an occasion to publicly demonstrate the personal courage that testified to the qualities of a man" (p. 85). There are, however, many substitutes for dueling to demonstrate courage. Furthermore, duels often arose in the military, and often during times of battle, where courage could easily be demonstrated without resorting to dueling.

In contrast, legal scholars have viewed dueling as a social norm substituting for legal proceedings in a court of law. Most conclude it eventually became an inefficient, or even irrational, replacement for traditional courts. ${ }^{4}$ Different legal scholars offer different reasons for why dueling arose as a substitute: courts were too costly, the offenses were too trivial, or courts were simply unwilling to deal with issues of honor. Posner (1996) views dueling as a social norm that prevented "disputes from exploding into feuds by formalizing and channeling the means of enforcement" (p. 1737). For Posner, dueling was inefficient because the state was better at settling disputes and avoiding serial violence than private individuals. ${ }^{5}$ Schwartz, Baxter, and Ryan (1984), come closest to an efficiency explanation of dueling by recognizing that dueling played a role in facilitating social interactions by helping to enforce good reputations, but they also view

4. If viewed as a court substitute, dueling appears to be a particularly inefficient social norm since the metaphor fits so badly: "The duel was like a lawsuit where the judge, after establishing that indeed there was a wrong, flips a coin to decide who, between the plaintiff and the defendant, should be executed for the wrong.... No doubt then, the duel often misfired, either because the challenge itself was wrongful and the challenged suffered death, or because the challenge itself was correct but the challenger suffered death.... To us, certain features are clearly ridiculous: the practice is random, it strikes down some of the community's most valuable citizens, and its sanction is not proportional to its harm" (Lessig, 1995, pp. 969-70).

5. A problem with this interpretation is that dueling was restricted to the aristocracy. Yet this group always had access to courts. If dueling was a court substitute, then the aristocracy should have avoided it and used courts instead. 
duels as containing "strong elements of ritual, myth, and symbolism that are reflections of the deeply felt value structure of the social group" ( $p$. 331). As a result, for them the motivation for dueling centers around the cultural value placed on honor.

Our purpose is to provide an economic explanation of dueling and its puzzling features, one not based on culture, honor, gender, or court substitution. We view the duel as a screening device separating individuals in a world where trust was an important mechanism for supporting political exchanges among a small ruling class. As a screen it filtered out marginal aristocrats who had not invested in unobservable social capital - an investment that constituted a bond to assure performance in the administration of government. The advantage of our screening model is that it explains the rise and fall of dueling, its unusual characteristics - limits on participation, the role of seconds, the evolution of weapons - and differences in dueling over time and location. Other theories of dueling not only fail to explain these aspects, but instead use them as evidence of dueling inefficiencies.

\section{Patronage, Social Capital, and the Dueling Screen}

Unlike modern bureaucracies, governments during the premodern era were staffed by aristocrats, and senior appointments were made primarily on the basis of patronage. ${ }^{6}$ The system of patronage as then practiced deviates fundamentally from appointments and promotions in the modern civil service. $^{7}$ There was no advertising for positions, no examination, no interview, and no requirement for professional qualifications. A civil servant often had no tenure in office and was expected to act on behalf of his

6. During the premodern era the alternative to patronage was the sale of offices. Selling offices was feasible when the incentives of the purchaser were generally aligned with the Crown. When there were incompatible incentives, patronage was used. See Allen $(1998,2002,2005)$ for explanations of purchase and patronage in the army, navy, courts, and treasury. As a general rule the great offices of the state were granted through patronage and occupied by aristocrats. The lessor offices were sold and occupied by the merchant class. This article addresses the high civil offices granted through patronage.

7. Also different were the mechanisms used to police commercial ventures of the time. See Greif $(1989,1993)$ or Milgrom, North, and Weingast (1990) for examples of how medieval traders were able to self-police cheating. 
patron. ${ }^{8}$ Although patronage rings of corruption and nepotism, it was a system of promotion from within a given class, based on personal connections, or social capital. At a time when monitoring inputs and outputs was difficult, trust and honesty were highly valued traits - seemingly even more valuable than skill and ability.

The critical question is, why would a patron trust his appointment? Our argument is that trust was based on critical levels of social capital - an inalienable asset that generates value through connections with other people. ${ }^{9}$ Because social capital requires the cooperation of others in the group for it to be useful, it is not a form of private property like physical or human capital. As such, it is not transferable to other levels of society, and investments in it are sunk. Social capital is costly to acquire and comes from attending the same schools, social events, clubs, and churches. Social capital is also acquired through education, marriage, business connections,

8. Patronage was not identical in all European countries, of course, but the general principle was the same. Consider, for example, the system of appointments in England during the eighteenth century. In 1726 there were only 179 peers in the country, and with such a small number politics could not help but be personal. At the top of the civil service was the king's household, which included all the Crown's ministers at the pleasure of the king: "The Court was the heart of political and social life, for all decisions taken, all places promised, from a turnkey to a bishopric, had to be discussed and argued with the King" (Plumb, 1963, p. 50). Ministers and members of Parliament would control different parts of the government, depending on their influence. Powerful ministers possessed massive amounts of control. Patronage was passed down level by level: minister to court official, deputy lieutenant, sheriff, and justice of the peace. From these positions other positions of local government were then handed out to those in favor (see Aylmer, 1961, p. 69, for a description). The result was a very clannish form of administration, but one where "patrons were careful to select members whose views would not compromise their relations with the government" (Plumb, 1963, p. 41). The entire system depended on the goodwill of its members and their ability to trust one another in exchanges where direct monitoring was almost always absent.

9. The literature on social capital defines it a number of ways, but the essential element is an association between people, either formal or informal, which facilitates trade through "trust." Trust potentially lowers the cost of trading through a number of mechanisms: information on exogenous types, coordination resolution, and reinforcement of social and personal mores. Here we model social capital as "hostage capital," and the future return from it is lost if agents indulge in cheating behavior. Our interpretation of social capital follows Coleman (1988). For discussions of the role of social capital in economics, see Dasgupta and Serageldin (1999) or François (2002). 
and family history. Social capital is often difficult to observe, because it depends on the quality of the interpersonal associations. ${ }^{10}$

Although it is commonly argued that the value of social capital lies in enhancing trade, for us social capital does this specifically by enforcing cooperative behavior among the aristocracy through its role as hostage capital. Individual aristocrats found lacking in some way, because of either unacceptable behavior or political practices, could be punished with ostracism when they had invested in social capital. An aristocrat, virtually by definition, is someone whose entire social life, business connections, and persona are based on inclusion within the aristocratic group. To be a social outcast in an aristocratic society rendered all one's stock of social capital worthless. As Frevert (1998) states, "To be regarded as a coward for avoiding a duel equaled expulsion from society, a social death sentence, to which possible death in a duel was obviously preferable" (p. 41). ${ }^{11}$ Thus, in aristocratic markets patronage was policed along the lines of Klein and Leffler (1981) or Camerer (1988), with one's social capital acting as a bond for good performance. There are many examples in the economic literature of individuals undertaking costly investments before trade in order to establish and signal credentials. However, in these examples the investment signal is observable. During the age of dueling, social capital investment was unobservable, and therefore aristocrats using social capital to police patronage appointments were left with the question: how can one tell if a given level of social capital is present?

The duel of honor provided the answer to this question: the duel was designed to screen for a critical level of social capital among the aristocracy seeking patronage appointments. Those individuals who rejected the duel demonstrated their social capital was too low, and they could not be trusted. Those who accepted the duel demonstrated sufficient social capital and were allowed to participate in aristocratic exchanges. Thus, the duel

10. The interpersonal associations might also be occasional, and knowledge of other interactions and acquisitions of social capital may be costly to obtain, making social capital too costly to observe.

11. Similarly, "[F]ailure to behave honorably was viewed with intense disfavor by the elites that accepted the dueling convention. As these elites were cohesive, loss of reputation, measured by the reduced opportunities for advantageous relations with other group members, could be very substantial" (Schwartz Baxter, and Ryan, 1984, p. 322). 
was not a substitute for reputation-based exchange; it was an institutional support necessary in light of the unobservability of social capital. Our theory is similar in spirit to the religious club literature explanations of sectarian sacrifices. Iannaccone (1992) and Berman (2000), for example, argue that religious sacrifices help eliminate free-riding within religious groups that provide mutual insurance for their members. Our model is also similar to Milgrom, North, and Weingast (1990), where law merchants and private commercial courts were designed to spread the word about who was honest among the traders participating in the court. In those cases and ours, an institutional device was used to indicate a prior investment encompassing a public good component.

In summary, the duel was not a signal for trustworthy "types," nor was it designed to assist in policing ordinary business transactions where trades could be self-enforced through reputations, efficiency wages, or courts. Rather, it was a low-cost screen used to select investors in unobservable social capital during the age of patronage. ${ }^{12}$ The duel was designed to be difficult to fake, easy to verify, and unenjoyable in and of itself. Exposure to dueling continued throughout one's life for two reasons. First, social capital depreciates, and dueling screened for a maintained level of social capital. Second, any given duel could be faked, and continuous dueling meant that at some point a real duel would be fought. Dueling, of course, had costs: it excluded large numbers of individuals from civil service; it often resulted in death or serious injury to talented people; it created an incentive for individuals to invest in acquiring dueling skills; and, although measures existed to mitigate it, at the margin cheating at duels took place. Hence, when patronage was ultimately replaced by a professional bureaucracy based on measured merit, dueling ceased to be practiced.

12. The issue of self-enforcement is critical to the discussion of optimal institutions. As has been mentioned, a king would grant an important position of state to an aristocrat in exchange for loyal service. Beneath this position would be many offices, some of which were sold, and some of which were further granted as patronage. Thus, an office was a source of wealth to both patron and king. The value of an office depended on the net income it could generate. This income was higher if cheating problems could be mitigated. Hence, the king and his chief appointments had a strong incentive to make sure the dueling screen worked. Likewise, those who dueled had a strong incentive to enter only those duels that would be recognized by the patron. The dueling codes were codifications of these self-enforcing practices. 


\section{The Dueling Screen Model}

We model dueling as a one-shot game in order to demonstrate how it can act as a screen for social capital. ${ }^{13} \mathrm{We}$ begin by assuming two separate employment markets. The first market is an elite, aristocratic, market where self-enforced, long term political trades take place. In the second market, individuals participate only in lower-valued market transactions, for example, producing agricultural products from an estate. Individuals in this second market are cut off socially from the elite group, and the payoff to participating in the second market is $\beta$.

Let there be $N$ individuals in the population, each born with a different level of social capital, $s_{i}^{0}$, distributed with an ex ante cumulative density function $F(s)$, and ranked from highest to lowest (i.e., $\left.s_{1}^{0}>s_{2}^{0}>\ldots s_{N}^{0}\right){ }^{14}$ The level of social capital at birth is observable and can be augmented at a cost. This investment is sunk and unobservable. After investment, an individual's ex post level of social capital is $s_{i}\left(\geq s_{i}^{0}\right)$. In an elite market exchange, individuals will be honest or dishonest, depending on whether they have the reservation level of social capital or not, defined as $s^{R}$. For simplicity we are assuming $s^{R}$ is just sufficient to police any elite exchange, and all elite exchanges are assumed to be homogeneous in value. ${ }^{15}$ Thus, if $s_{i} \geq s^{R}$, individual $i$ is honest; if $s_{i}<s^{R}$, individual $i$ is dishonest.

The total gains from exchange in the elite group are a positive function of the number of people involved. The aggregate gains from trade for the group are given by

$$
G=g(n)
$$

where $n$ is the number participating in elite trade, $g_{n}>0$, and the size of $n$ depends on the benefits and costs of acquiring the reservation level of

13. Treating dueling this way captures almost all of the institutional detail we discuss later and greatly simplifies the analysis. If one treats the one-shot game as simply the last period, it is straightforward to convert it to a repeated game. Interested readers may contact the authors for the more general model.

14. In the graphs we assume $F(s)$ is rectangular.

15. Not setting higher reservation levels of social capital for higher levels of patronage appointments is a strong simplifying assumption, but there is no evidence in the historical record that any "ranking" of duels existed to police these different appointments. 
social capital. The marginal individual who invests just enough to enter the elite group has an ex ante level of social capital equal to $s^{*}$, and we call this the equilibrium cut-off social capital level. That is, if an individual has an ex ante social capital level equal or above $s^{*}$, then ex post he participates in elite trade and ends up with a social capital level $s^{R} .{ }^{16}$

Honest members of the elite group benefit from two sources. First, they share in the total gains from political trade. Second, they interact socially in the elite group, and for simplicity we set the dollar benefit of this social interaction equal to the individual's level of social capital. Hence, an elite member earns

$$
\begin{aligned}
& \frac{g(n)}{n}+s_{i}, \quad \forall s_{i} \geq s^{R} \\
& =\bar{g}(n)+s_{i},
\end{aligned}
$$

where the first term is the shared gain from trade, and the second term is the value of social interactions. If a member of the elite group is dishonest, then his payoff is equal to $\lambda \bar{g}(n)$, where $\lambda>1$. That is, he takes a disproportionate share of the gains, but he does not participate socially in the group.

The timing of the dueling screening game is straightforward.

1. The king chooses the reservation level of social capital (which, along with the cost of investment, determines the size of the elite group, $\left.\left[1-F\left(s^{*}\right)\right]\right)$, and the probability of dying in a duel, $\pi$;

2. Individuals decide their social capital investments;

3. Individuals decide whether or not to duel; and

4. Individuals within the elite group decide whether or not to be honest.

The purpose of the duel is to screen out those low-social-capital individuals who will cheat in the elite trading market. In order to focus on the screening function of the duel, we develop our model in three stages. First, we treat social capital as fixed and observable to show how the elite group size is determined. Second, we allow social capital to be variable but still observable to show the relationship between the reservation level of social

16. We are assuming, for simplicity, those born with $s^{*}<s_{i}<s^{R}$ invest only until they reach the minimum level to join the group. It is reasonable, but unnecessary, to assume an individual may invest more than this because of their value of social interactions. 
capital, $s^{R}$, and the equilibrium cutoff level, $s^{*}$ in the ex post distribution of social capital. Finally, we examine the more realistic case, in which social capital is variable and the investment is unobservable, and use this model to derive the screening conditions.

\subsection{Optimal Size of Group: Social Capital Observable and Fixed}

We begin by determining a benchmark group size $(n)$ in the trivial case where the level of social capital is observable and fixed-that is, no investment is possible. The size of the elite group depends on the king's announcement of the necessary level of social capital to join. The king wants to maximize the aggregate gain from trade in the elite group, and so he wants to choose a reservation level of social capital such that everyone in the elite group is honest. ${ }^{17}$ Since members will be honest so long as $\bar{g}(n)+s_{i} \geq \lambda \bar{g}(n)$, the minimum level of social capital to induce honesty, $s^{R}$, is given by

$$
\bar{g}\left(n\left(s^{R}\right)\right)+s^{R} \equiv \lambda \bar{g}\left(n\left(s^{R}\right)\right) .
$$

Since social capital is fixed, $s^{*}=s^{R}$. Figure 1 shows the fixed distribution of social capital. Had the king announced $s^{\prime \prime}$ to be the level of social capital necessary to enter the group, $F\left(s^{R}\right)-F\left(s^{\prime \prime}\right)$ individuals would not be honest. If the king announced $s^{\prime}$ as the level of social capital necessary to enter the group, then $F\left(s^{\prime}\right)-F\left(s^{R}\right)$ individuals (equal to the shaded region) would be ruled out of trading even though they had sufficient

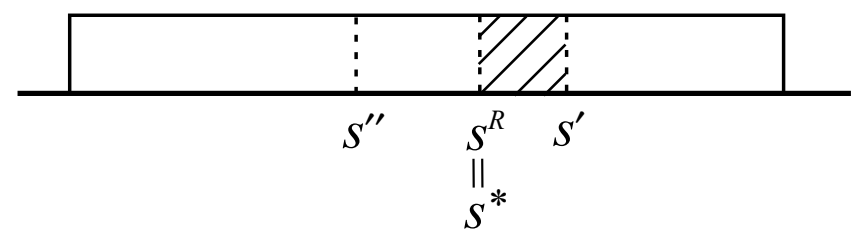

Figure 1. Optimal reservation social capital in fixed distribution.

17. For simplicity we assume it never pays the king to have a dishonest member in the elite group. 
social capital to be honest. Since no investment is possible and social capital is observable, those individuals with social capital levels above $s^{*}=s^{R}$ participate in the elite political market, while those with social capital levels below $s^{*}=s^{R}$ are left with only trades outside the political sphere in the nonelite group and earn a per-period payoff of $\beta$. In this case there is no need for a dueling screen.

\subsection{Relationship between $s^{*}$ and $s^{R}$ : Social Capital Observable but Variable}

To gain intuition regarding the size of the group and the relationship between the reservation and equilibrium cutoff levels of social capital, consider the case in which social capital is observable and individuals make observable investments in social capital. Now there is a two-stage problem where the king chooses $s^{R}$, and individuals then choose whether or not to invest. Solving backward, consider the second-stage problem for a given level of $s^{R}$. If an individual is born with $s_{i}>s^{R}$, there is no need for investment. If an individual is born with $s_{i}<s^{R}$, then investment occurs if the net gains from investment are greater than those from not investing. The equilibrium cutoff level of social capital, $s^{*}\left(s^{R}\right)$, is determined by the marginal individual, and is given by

$$
\bar{g}\left(n\left(s^{R}\right)\right)+s^{R}-C\left[s^{R}-s^{*}\left(s^{R}\right)\right] \equiv \beta,
$$

where $C\left(s^{R}-s^{*}\left(s^{R}\right)\right)$ is the cost function for acquiring the required level of social capital. In the first stage, the king maximizes the gains to the elite group, again choosing the $s^{R}$ that ensures everyone in the elite group is honest. An interesting implication of our social capital model is that the ex post distribution of social capital has a gap in it, as shown in Figure 2.

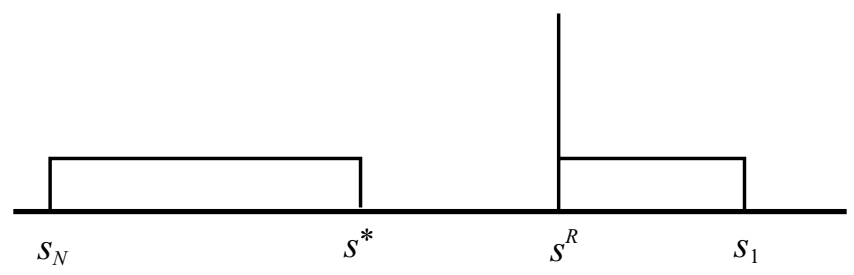

Figure 2. Ex post investment social capital distribution. 
When social capital is used to police elite exchanges, and when it is possible to invest in social capital, there is not a continuum of types after investment. Rather, a large social gulf lies between the two groups, as is often observed between aristocrats and commoners. As in the benchmark case, when social capital is observable and variable, there is still no need for a dueling screen.

\subsection{The Dueling Screen: Unobservable Investment}

When the social capital investment is unobservable, a mechanism is necessary to screen potential appointees for the reservation level of social capital, because individuals born with capital levels lower than $s^{R}$ might pretend they have made the costly investment, in order to enter the group. To "pretend," in our context, means to participate in the elite group under the pretense one has the necessary social capital, $s^{R}$. Recalling that the probability of dying in a duel is $\pi$, individuals will duel and be honest so long as $(1-\pi)\left[\bar{g}(n)+s_{i}\right] \geq(1-\pi) \lambda \bar{g}(n)$, which reduces to equation (3) and means dueling does not effect the optimal size of the elite group. ${ }^{18}$

To determine the conditions for dueling to act as a screen, let us consider the decision of an individual with social capital $s^{*}<s_{i}<s^{R}$ to invest in social capital as represented in Figure 3. ${ }^{19}$ Using backward induction, consider the choice of a pretender at the third stage of the game tree who is deciding whether to cheat or not. By the construction of $s^{R}$, for the pretender it is always true that $(1-\pi)[\bar{g}$ $\left.\left(n\left(s^{R}\right)\right)+s_{i}\right]<(1-\pi) \lambda \bar{g}\left(n\left(s^{R}\right)\right)$, so the pretender will always cheat at the last node. On the other hand, a legitimate investor in social capital will always be honest. At the last node the cost of investment is sunk, and the investor compares only the values of being honest or dishonest. Since by construction $(1-\pi)\left[\bar{g}\left(n\left(s^{R}\right)\right)+s^{R}\right] \equiv(1-\pi) \lambda \bar{g}\left(n\left(s^{R}\right)\right)$ for the investor, the investor is honest. We can thus replace the third stage of the game with the relevant values. At the second stage of the game tree, individuals

18. We assume the value of death is normalized to zero. Although a spectrum of injuries could result, here we model the game as having only two outcomes: death and survival. Note that we ignore strategic issues between the two duelists. As we point out later, the rules for dueling were designed to minimize this problem.

19. Those born with social capital greater than $s^{R}$ will satisfy the dueling conditions, while those born with levels below $s^{*}$ will not be allowed to duel. Hence, we need to consider only the investors. 


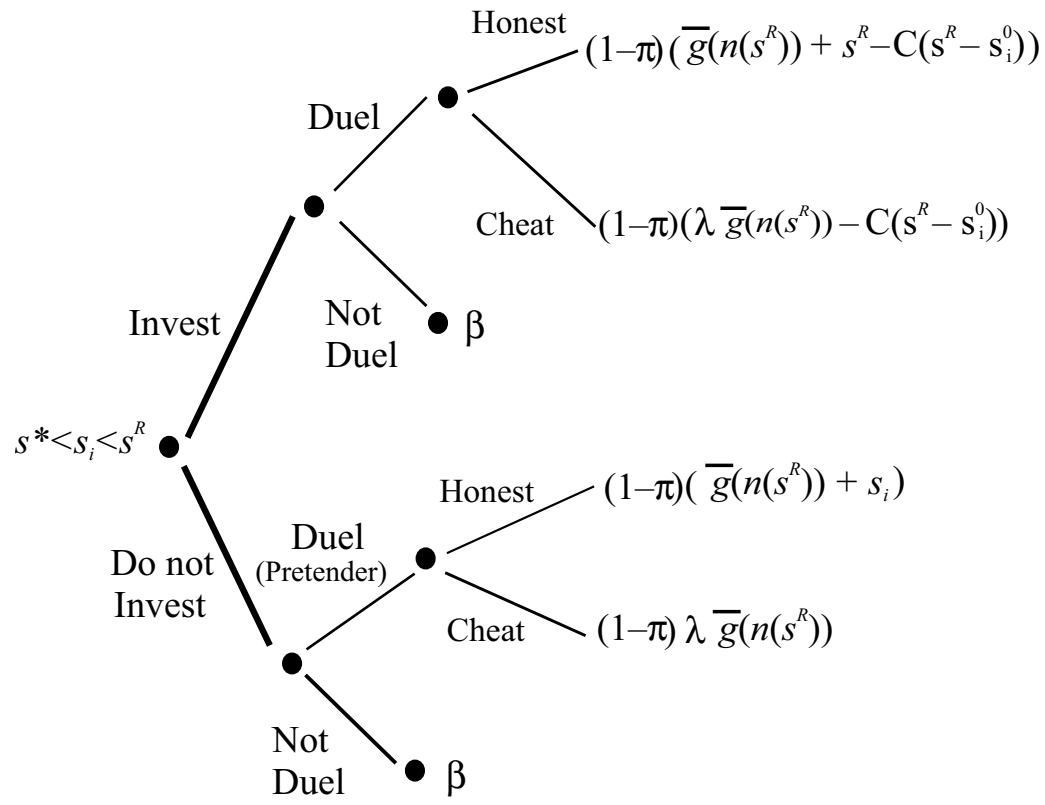

Figure 3. Social capital investment decision.

decide whether or not to duel. In order for dueling to act as a screen, pretenders must always reject a duel. This implies that

$$
(1-\pi) \lambda \bar{g}\left(n\left(s^{R}\right)\right)<\beta .
$$

Similarly, the individual who actually invested in social capital must always accept a duel. ${ }^{20}$ This implies that

$$
(1-\pi)\left[\bar{g}\left(n\left(s^{R}\right)\right)+s^{R}\right] \geq \beta .
$$

Moving back to the first node, for dueling to be an effective screen for social capital investments, individuals must prefer to invest rather than pretend an investment. Thus, the third screening condition is

$$
(1-\pi)\left[\bar{g}\left(n\left(s^{R}\right)\right)+s^{R}\right]-C\left(s^{R}-s_{i}^{o}\right) \geq \beta .
$$

Thus, the screening conditions are as follows:

20. Recall the costs of investment are sunk, and so are not included in equation (6). 
1. Pretenders prefer to not duel: equation (5);

2. Investors prefer to duel: equation (6); and

3. Individuals prefer to invest rather than pretend: equation (7).

If equation (7) is satisfied, so is equation (6), which means the duel is designed by choosing $\pi$ from the first and third screening conditions. If $\pi$ is set too high, social capital investors reject duels and the screen is ineffective. If $\pi$ is set too low, individuals do not invest, they do accept duels, and there are cheaters on political trades in the elite group - again the duel is ineffective. Thus, the king uses equations (5) and (7) to determine the optimal lethality of the duel. Solving each equation for $\pi$ we get

$$
\left[1-\frac{\beta-C\left(s^{R}-s_{i}^{0}\right)}{\bar{g}(n)+s^{R}}\right] \geq \pi \geq\left[1-\frac{\beta}{\lambda \bar{g}(n)}\right]
$$

The optimal $\pi$ is chosen so that individuals born with social capital levels $s^{*}<s_{i}<s^{R}$ invest and accept duels. Presumably the king sets $\pi$ at the lowest feasible level, given the costs of killing off members of the aristocracy. Anyone who rejects a duel demonstrates he has not made the relevant investment and should not be trusted.

\subsection{Duels versus Lotteries and Russian Roulette}

Any screening device based on self-sacrifice could reveal social capital and sift trustworthy elites. Why would dueling be more efficient than a lottery, Russian roulette, or some other such mechanism? Consider a lottery, where those interested in participating in government submit their names to a gamble with some probability of death. In such a lottery the probability of dying could be random, no effort would be made to train for the lottery, no one would be born with an inherent advantage, and presumably the cumbersome procedures of the duel could be avoided.

The problem is that a lottery requires monitoring since the outcome is subject to manipulation. Who would trust such a lottery? The cost of convincing potential participants that such a lottery screen is indeed random might be prohibitively expensive. The same problem holds for any 
screen requiring the administration of a third party. ${ }^{21}$ On the other hand, the competitive, adversarial nature of the duel gave it three advantages over alternative, administered screens. First, duelists could trust the honesty of the duel because it was under their control and each had an incentive and ability to ensure fairness. Second, members of the elite group could trust the fairness of the dueling screen because of its clear all-or-nothing character, role of seconds, imminent occurrence, and other institutional features provided a screen not easily subject to manipulation. Third, the competitive nature of duelists attempting to prove their social capital in an effort to be eligible for patronage meant successfully "staged" duels would yield only short-term benefits. Dueling involved self-selected duelists who had (incomplete) information on the social capital of others in their peer group. Individuals who entered the elite ruling group on the basis of a staged duel would likely find themselves soon challenged by more legitimate holders of social capital. Hence, the private duel, with its verifiable fairness, restrictions on manipulation, and constant threat of occurrence made it a low-cost screen. ${ }^{22}$

\section{Predictions and Tests of the Dueling Screen Hypothesis}

\subsection{Limits on Participation}

The screening model, in contrast to other dueling theories, makes a strong prediction on dueling participation. First, since social capital acquired at birth is observable, there is no need for individuals born with social capital well above the critical level to enter a duel-it is already known they meet the threshold level. Hence, the very highest members of society should not be allowed to duel. Second, since it never pays individuals with levels of social capital below $s^{*}$ to invest, these individuals should also be barred from participating. According to the dueling model, these individuals should not want to duel. However, extremely low social capital individuals may duel for other reasons - they might be

21. Milgrom, North, and Weingast (1990) note that a problem with law merchants and private judges was their susceptibility to bribes. Costly institutional barriers had to be erected to prevent this.

22. In these regards we see the real similarity between courts and dueling. Courts rely on adversarial proceedings to generate truth; courts are trusted because outcomes are easy to review and appeals make manipulations difficult. 
exceptional duelists, they might stage the duel, or they might use the duel to settle a dispute-but, in all cases, allowing these individuals to duel reduces the value of the screen. Low social capital individuals who duel impose social costs with no offsetting benefits, and they should be barred from the practice.

Thus, dueling is predicted among the marginal aristocracy. Consider Figure 4. Individual $s_{j}$ was born with a low level of social capital and will never find it profitable to invest to $s^{R}$, and, therefore, any attempt at dueling is not a credible signal of an investment in social capital. Since the initial level of social capital is observable, society avoids this problem by not allowing those born with social capital levels below $s^{*}$ to duel.

The predicted limits on participation are consistent with the historical facts of dueling. Several classes of individuals were not allowed to duel, nor were they allowed to be challenged. Royal family members, for example, were excluded from dueling, and high nobility were often prevented from it. ${ }^{23}$ In addition, during times of war, and especially during battles, military officers were not allowed to duel. Officers were not allowed to duel with officers of a higher rank. Commercial classes, merchants, bankers, and the like were not allowed to duel, nor were

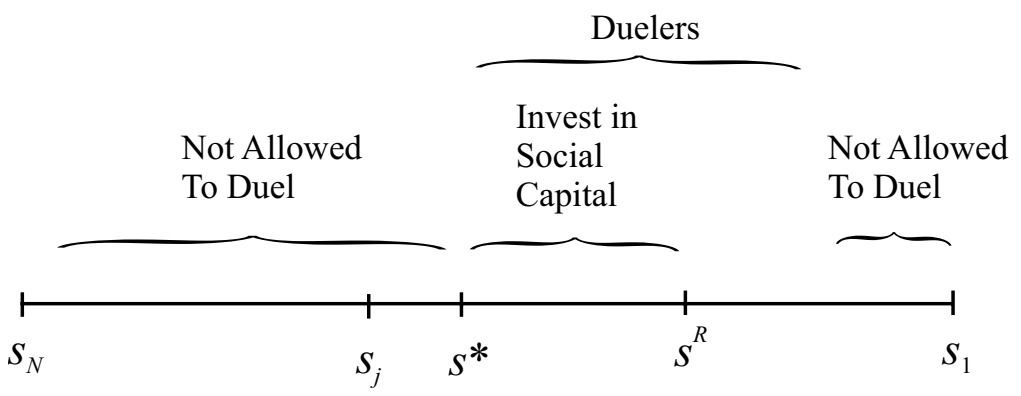

Figure 4. Ruling out noncredible participants.

23. [C]ourts of honour attempted to deter challenges made for frivolous reasons. These courts were particularly common in the 16th century and were most useful when the higher nobility was involved. Monarchs_-Elizabeth I most notably_kept a close eye on their courtiers and intervened to prevent the loss of valued advisors. But lesser aristocrats and those with patrician pretensions either duelled impetuously or ignored the existing avenues of mediation" (Halliday, 1999, p. 3). 
Jews. ${ }^{24}$ Indeed, it would appear that most dueling took place among the lower levels of the ruling elite. ${ }^{25}$

Society prevented the lowest members of European society from dueling by making dueling illegal for everyone, but it allowed aristocrats the privilege of dueling without concern over arrest. Ironically, those making antidueling laws were the very individuals most active in dueling. Many writers on dueling find the practice of dueling among legislators incongruent with laws banning the practice. ${ }^{26}$ This puzzle disappears when dueling prohibitions are viewed as part of a screening mechanism. Although aristocrats convicted of dueling could always receive a pardon, commoners caught engaging in a fatal duel were charged with murder (see, e.g., Steward, 2000, p. 6).

This important point distinguishes legal theories of dueling from the screening hypothesis. Most legal writing on dueling argues the state actually wanted to eliminate dueling through the use of legal sanctions, and that the antidueling laws were ultimately successful in changing social norms and eliminating the practice. There are several problems with this theory that disappear with the screening hypothesis. First, dueling was always illegal, and yet it lasted for centuries. Second, the antidueling laws were enforced and effective-lower-class individuals were effectively

24. As a general rule, Jews were excluded from the aristocracy and political appointments, though exceptions are found. Thus it is consistent they would be ruled out of duel participation. There is a final class of individuals who, although not barred from dueling, virtually never dueled: women. Although there are records of women duels, the numbers were trivial. We would argue the lack of dueling resulted from their lack of participation in civil administration.

25. The duel was designed for individuals like John Churchill. Born to a poor squire, he entered the household of the Duke of York as a simple page. Churchill's life was an example of constantly investing in social capital. Along the way to becoming the Duke of Marlborough, he fought at least two duels to demonstrate this investment.

26. An interesting aspect regarding dueling participation, was that those qualified to duel were expected to duel in every legitimate duel. The condition of repeated dueling participation existed for at least two reasons: first, to prevent staged or fake duels, since success in a fake duel did not prevent further dueling; second, to encourage marginal aristocrats to maintain their social capital, given that it could depreciate. When extremely important individuals found themselves in duels, the social reaction was quite negative. See, for example, Baldick (1965, pp. 104-6) for the negative public reaction to the Wellington-Winchilsea duel. 
barred from dueling. Finally, when dueling ended it was not replaced by law but by a meritocracy. ${ }^{27}$

\subsection{The Cause, the Challenge, and the Consequence of Duels}

One of the most obvious predictions of the screening hypothesis is that the grounds for the duel, the identity of the challenger, and the outcome are all irrelevant. The importance of the duel was its function as a screen, and participants - as either the challenger or the challenged, whether they won or lost-demonstrated they had invested in social capital.

There is strong evidence for this in the historical record. Unlike earlier judicial duels fought over capital crimes, duels of honor were fought over any slight against one's character, family, or reputation. McAleer (1994, p. 47), writing on the duel in Germany, noted that virtually all duels were the result of either impoliteness, cursing or attribution of shameful qualities, or touching another's person. Within these broad categories, there existed an almost limitless number of grounds for a duel, and the historical record shows that duels were fought over trivial slights, as well as issues of great slander.

In addition to the irrelevance of the dueling grounds, there was no social advantage to challenging or winning. Who initiated or became the victor was irrelevant in a duel. Parker (2001) notes that "the restoration of honor did not depend on the outcome of the confrontation. Ideally, a wellfought duel reconciled the two adversaries, reestablished mutual respect, and 'cleansed' the stain caused by the original insult" (pp. 8-9). Indeed, one of the great ironies of dueling - but an implication of screening - was the subsequent renewal of friendships among adversaries. ${ }^{28}$

27. We agree with Wells (2001), who suggests that the view that the law can be used to change social norms is mostly in the imagination of those seeking to manage social behavior. Dueling ended when its role as a screen ceased, not because it was illegal. Dueling was reserved only for aristocrats, those individuals for whom civil service and the administration of the kingdom was an option. As Kiernan (1988) states, "Its affiliation was always and everywhere with social groups occupying a pre-eminent and privileged position, or inspired by the striving towards such a position" (p. 2).

28. Histories of individual duels are replete with such stories. Samuel Pepys's diary contains references to at least 13 duels. One is a duel between Tom Porter and a Mr. Bellasses. Porter made a fatal wound, and Pepys records the following: "[H]e called T. Porter and kissed him and bade him shift for himself 'For Tom, thou hast hurt me ... I would not have thee troubled for what thou has done." Then Pepys notes "both of them most extraordinary friends" (1970, Vol. 8, p. 364). 
Trivial grounds for dueling have been used by social historians as evidence of its irrationality or manifestation of inherent male violence. Kiernan (1988), in one of the most comprehensive studies, states, "The triviality of many disputes, which satire could scarcely exaggerate, and the willingness of so many men, young men in particular, to risk death, maiming, or exile, on the spur of the moment, suggest an infantile mentality, minds incapable of serious thought, and reacting to any stimulus like automata" (p. 117). ${ }^{29}$ Similarly, legal theorists often point to the use of deadly force in the face of trivial infractions as evidence of inefficiency. On the contrary, these were the characteristics of an efficient screen.

\subsection{Exogenous Probabilities through Dueling Rules: The Code Duello}

If dueling acted as a screen, then it was critical that the probability of death was exogenous to the participants; otherwise, the probability would violate the screening conditions. ${ }^{30}$ With endogenous probabilities, individuals invest in skills that alter the probabilities in their favor. Hence, a good marksman or a good fencer may find a given duel acceptable simply because he stands a good chance of winning and not because he has made the necessary investment in social capital. An additional problem with endogenous outcomes is the inefficiency that results from investments in dueling skills where an "arms race" develops as individuals overinvest in talents to increase their odds of winning. In the language of dueling, there was to be a "level playing field," and this essentially meant the outcome was to be random. ${ }^{31}$

29. Similarly, Frevert (1998) suggests that the trivial nature of dueling grounds was simply the result of a culture of sensitivity: "The conflict was generally triggered by an insult or an offense to one's honor, the definition of which might depend on the individual involved. The early modern period was marked by extreme sensitivity in the perception of such offenses" (p. 38). On the other hand, Schwartz, Baxter, and Ryan (1984), are right: "The duel, in these [trivial] circumstances, may be viewed as a means for the two parties to demonstrate that, whatever the facts of the precipitating incident, they are in fact honorable people" (p. 345).

30. This implication stands in contrast to the legal theories, which view random outcomes of trials as inefficient.

31. "A fair duel was a game of chance that displayed the willingness of both principals to die for their honor, not their skill at inflicting pain or death" (Freeman, 2001, p. 178). 
An important method of achieving randomness was the institution of dueling rules. ${ }^{32}$ The Code Duello was a set of rules drawn up by Irish gentlemen delegates at Clonmel Summer Assizes in $1777 .{ }^{33}$ Although the code was prescribed for general use in Ireland, it was generally followed in England, the Continent, and America with small variations throughout the $19^{\text {th }}$ century; in fact, the 26 rules were called "The Twenty-Six Commandments." These rules delineated the rights of the challenged and challenger, grounds for terminating the duel, rules for conducting the duel, and the rights and obligations of the seconds. Many of these rules contributed to making the probability of death exogenous.

For example, pistol duels were conducted with inaccurate weapons, and being hit was largely a matter of chance. This randomness was enhanced by several rules.

Rule 3. If a doubt exists who gave the first offense, the decision rests with the seconds; if they won't decide, or can't agree, the matter must proceed to two shots or to a hit.

Rule 17. The challenged chooses his ground; the challenger chooses his distance; the seconds fix the time and terms of firing.

Rule 18. The seconds load in presence of each other.

Rule 20. In all cases a miss-fire is equivalent to a shot, and a snap or non-cock is to be considered as a miss-fire.

Rule 22. Any wound sufficient to agitate the nerves and necessarily make the hand shake, must end the business for that day.

The pistol duel was designed to provide a limited number of attempted shots since better marksmen could better calibrate the weapon and gain an advantage with unlimited shooting. The duel also had a set time for shooting and required seconds to load. An expert with the pistol would

32. These are taken from Cochran (1963, pp. 74-76). It is not clear what the social historical or legal implications are regarding dueling rules. Both allow for rules to exist, but neither seems capable of explaining the goal of randomizing the outcome. Indeed, this seems a strong refutation of these alternative approaches.

33. There were many sets of rules, with the first widely popular set published in Venice in 1550 by Girolamo Muzio. In these early rules, several features are common: seconds must be present; deadly weapons must be used; generally, the challenged was allowed the choice of weapon, and other, but not all, features of the duel that influenced the absolute and relative lethality; and the duel was to take place without delay, usually the next morning. 
have an advantage in correctly and quickly loading his weapon. Rules 17 and 18 eliminated this advantage. Finally, to the extent a better duelist was less likely to become agitated by a wound, rule 22 worked against him. Other rules developed to randomize events. For example, not only was rifling the barrel not allowed, but also dueling pistols had short barrels (reducing accuracy), and aids in aiming were also discouraged. ${ }^{34}$ McAleer (1994) points out, "The piece was ordinarily fitted with sight and bead, but these must have been removable since most duels were prosecuted minus their aid-and for the same reason that groves of trees were avoided as dueling sites: so as not to inordinately channel one's aim" (p. 65).

A series of rules restrict expert duelists or staged duels. For example, consider the following rules.

Rule 6. If A gives $\mathrm{B}$ the lie, and $\mathrm{B}$ retorts by a blow ... no reconciliation can take place till after two discharges each, or a severe hit.

Rule 7. But no apology can be received, in any case, after the parties have actually taken ground, without exchange of fires.

Rule 13. No dumb shooting or firing in the air is admissible in any case.

Staged duels reduced the effectiveness of the dueling screen. Insults could be traded and a duel agreed to that in actual fact was theater rather than real. As rules 6 and 7 state, however, certain events automatically triggered a duel, and once duelists were on a field, shots must be fired. Rule 13 states shots must be fired at the opponent. ${ }^{35}$ All duels required

34. It is worth pointing out that the impediments placed on pistols made them inaccurate, not ineffective. Dueling pistols were well crafted, expensive, and looked after. They were expected to work every time. In the spirit of the literature on optimal punishments, one might think more accurate weapons, leading to fewer costly duels might be more efficient. However, accurate weapons open the door for training and marksmanship, which diminish the value of the duel as a screen.

35. Even if shots were directed at nonfatal parts of the body, in an age lacking antibiotics any wound could kill. Indeed, most deaths from dueling resulted from infections rather than the wound itself. This is why duelists often stripped to the waist: To compound the danger factor yet more, the bighearted gesture of shooting over an opponent's head or firing off into the woods, as often portrayed in fantasy, was strictly forbidden by the dueling codes.... Were the seconds to note such a conspicuous miss, it was their duty to rush between the combatants before an opponent could return fire, to reprehend the offender and begin anew" (McAleer, 1994, p. 69). 
seconds, and usually had a doctor and others in attendance. All of these features lowered the chance of fake duels.

Although it varied from time to time, a general theme in dueling rules was to assign rights in favor of the challenged. For example, consider the following.

Rule 15. Challenges are never to be delivered at night, unless the party to be challenged intend leaving the place of offense; before morning; for it is desirable to avoid all hot-headed proceedings.

Rule 16. The challenged has the right to choose his own weapon, unless the challenger gives his honor he is no swordsman.

Rule 16 was not always found in earlier rules, but it took away a major advantage of the challenger and leveled the playing field considerably. As Rule 17 states, other rights regarding the ground and the timing of shots were not held by the challenger. Indeed, since challenges could also be provoked, we should not be surprised that rights were also held by the challenger and the seconds. In German dueling codes there was a complicated sets of rights to the "insulted" party, depending on the level of insult. McAleer (1994) notes these rules were designed to prevent "ruffians with strong arms and practiced eyes to go around intentionally picking fights" (p. 47). Rule 15 essentially protected unassuming victims from accepting duels from strategic challenges in the heat of the moment. A final set of rules pertained to the ending of the duel, and essentially amounted to "first blood." Duels, especially toward the end of dueling, were usually not fatal. Aside from efforts to make the duel random, the "first blood" rules also reduced the chance of death. The rules on limiting shots have already been mentioned, but similar restrictions held true for swords.

Rule 5. If swords are used the parties engage until one is well blooded, disabled, or disarmed; or until, after receiving a wound, and blood being drawn, the aggressor begs pardon.

In fencing duels gloves were generally not worn, which meant most first wounds were to the armed hand since it was closest to the opponent's blade. The "first blood" rule in fencing duels eliminated any advantage one duelist might have due to physical size or strength. Since each duelist used a weapon identical to the other, the opponents' armed hands were the same sword distance away from each other. This was not true of the opponent's 
torso, since individuals with longer reaches have an advantage in attacking the body. There were other restrictions on sword duels that hindered excellent fencers: "The duelist was not allowed to follow-up an attack which had disarmed his opponent or had caused him to stumble and fall. It was impermissible to transfer a blade from one hand to the other. Parrying of the opponent's blade with one's free hand was not allowed" (McAleer, 1994, p. 61).

In fencing duels it was more difficult to level the playing field than in pistol duels, which explains why dueling evolved into pistol competitions. ${ }^{36}$

\subsection{The Role of Seconds}

One of the most important aspects of dueling was the presence of seconds. These men were chosen by the duelists and played a role from the beginning to the end of a duel. All communication and negotiation was done between the seconds, not the duelists. Weapons were inspected and armed (if pistols) by seconds. Social historians often contend the role of seconds was little more than ceremony allowing the aristocracy to view dueling as less barbaric and above the mere brawl of the common man. ${ }^{37}$ To the legal scholar dueling substituted for court actions, so the role of the second was to act as a mediator and judge, and to prevent the action from escalating in violence. ${ }^{38}$

Under our screening hypothesis the seconds play three different roles. First, screening requires the second to prevent strategic duels, and to prevent his friend from becoming the victim of an opportunistic excellent

36. McAleer (1994) notes that in Germany during the nineteenth century, only about one in four duels were with sabers (p. 58). He also notes the difficulty in equalizing the duel with sabers (p. 63).

37. "The purpose of such rules [including the role of seconds] was to elevate the single combat of honor above ordinary quarrels and to give it a certain outward dignity" (Frevert, 1998, p. 39).

38. Schwartz et al. state: "The seconds could, in principle, have engaged in the settlement process in two ways. Under one conception, each second would attempt, like an attorney representing a party to litigation, to achieve the best possible results for his principal, given the probabilities of the various outcomes of the duel and the costs of preceding to successive stages. The second possibility is that the seconds were obliged to conduct settlement negotiations so as to achieve a result which accorded with the merits of the dispute giving rise to the challenge" (Schwartz, Baxter, and Ryan, 1984, p. 337). 
duelist. Second, these men would have indirectly made collusion among duelists more difficult. ${ }^{39}$ Third, the second was to ensure the odds of dying were as fair as possible. Weapons were to be inspected and guns were to be loaded; conditions such as the placement of the sun, the firmness of the ground, location of trees (for aiming), and so forth, were to be considered. ${ }^{40}$ These roles explain the confusing observation of seconds at times refusing duels and other times insisting they take place. The second's role was not to avoid all duels, but only those duels that were not legitimate. ${ }^{41}$

\subsection{Changes in Lethality Across Jurisdictions}

In the screening model the reservation level of social capital is chosen such that equation (7) is binding. From that equation it is clear there must be an inverse relationship between the cost of acquiring social capital and the lethality of the duel; that is, if social capital is more expensive to acquire, the duel is less lethal. Essentially, social capital and lethality are substitutes. Larger investments in social capital mean larger streams of earnings in the elite group, so anyone caught cheating on an exchange stands to lose significantly more, and, as a result, the chance of loss of life in a duel need not be as high.

It is reasonable to suppose aristocratic societies had higher costs of acquiring social capital than more egalitarian ones. It is practically the definition of aristocracy that movement through social ranks, including

39. First, simply having more individuals involved in a duel makes collusion more difficult. Second, since a doctor and other notables generally attended duels, seconds were required to carry out the duel rules that raised the cost of collusion. Finally, seconds involved in collusion must be paid off, since their social capital is diminished by a successfully staged duel.

40. The cover picture of Murray's 1984 catalog of Lieutenant Colonel William Orbelo's collection of American dueling pistols is of two .60-caliber flintlock pistols. However, the inside jacket states, "Interestingly, one pistol is smooth-bore and the other rifled. In many early dueling codes rifled barrels were illegal, although some gunmakers produced guns with secret rifling, which was invisible at the muzzle" (p. 4). It was a critical job of the second to minimize such practices.

41. The legitimacy of the duel and the behavior of the duelist were extremely important. To misbehave in any way could often be as serious as turning down a duel. Pepys (1970) alludes to such a situation in one of his many brief comments on duels of his day: "[T] he world says that Mr. Mountagu did carry himself very poorly in the business and hath lost his honour forever with all people in it" (Vol. 3, p. 157, 1970). Unfortunately, Pepys does not record what Mr. Mountagu did. 
those within the upper class, is difficult. In egalitarian societies, social status often depends on a few dimensions, sometimes just wealth. Movement from the middle class to the upper class in Europe was considerably more difficult than in the New World, and as a result dueling is predicted to be less lethal in Europe.

The first reported duel in America was between two servants of a Massachusetts gentleman in 1621 (Baldick, 1965, p. 115). The most famous duel in history, the Burr-Hamilton duel in 1804, was also an American duel. ${ }^{42}$ Although no unique American dueling rules arose and American duels were conducted according to the same procedures as European duels, the two duels just mentioned illuminate the essential differences. First, duels in the Americas were essentially open to everyone. There were duels among gentlemen and commoners, landholders and the landless. ${ }^{43}$ Second, the duel in America was more deadly than those in Europe. Baldick (1965) in quoting de Tocqueville, states as follows:

"In Europe one hardly ever fights a duel except in order to be able to say that one has done so; the offence is generally a sort of moral stain which one wants to wash away, and which most often is washed away at little expense. In America one only fights to kill; one fights because one sees no hope of getting

42. Given its notoriety, the Burr-Hamilton duel is worth examining in more detail. Both participants were members of the ruling elite of the time. Hamilton did not want to fight the duel and wrote a letter during the negotiations, outlining his beliefs on the practice. In it he states he opposed dueling because of his religious principles, his concern for his wife and children, his obligation toward his creditors, and his lack of ill will towards Colonel Burr; he felt he would gain nothing from the fight. On the other hand, he felt it was unavoidable because to go through with it would give him "the ability to be in future useful, whether in resisting mischief or effecting good, in those crises of our public affairs, which seem likely to happen, and would probably be inseparable from a conformity with public prejudice in this particular" (Kline, 1973, p. 401). Although Burr killed Hamilton, he was never convicted of murder. Indeed, he was allowed to finish his term as vice president, and in 1812 he resumed his New York law practice and continued in that profession for 24 years. He was buried in 1836 with full academic and military honors. All aspects of this story are consistent with our screening model.

43. In addition to Burr and Hamilton, General Andrew Jackson, the future president, fought in a duel, as did senators, and Supreme Court justices. Abraham Lincoln even met on the field of honor to fight a duel in 1842 with broadswords. His opponent, James Shields, had second thoughts, and the duel was not carried out (Steward, 2000, p. 126). 
one's adversary condemned to death. There are few duels, but they almost always end fatally" (p. 115).

The differences in American dueling are consistent with our model. Since the colonies lacked a well-defined aristocracy, endowed social capital was less easily observed. As a result, there were no restrictions on who could duel. Furthermore, an egalitarian society had more lethal duels. ${ }^{44}$ European duels of the nineteenth century had a fatality rate of around $2 \% .{ }^{45}$ In contrast, Schwartz, Baxter, and Ryan (1984) claim that the fatality rate in U.S. pistol duels was 1 in 14 , or slightly more than $7 \%{ }^{46}$ In addition, American dueling was more common in the south than in the north. Given that the social structure of patronage was stronger in the south, this is also consistent with our hypothesis.

\subsection{No Patronage, No Dueling: The English Commonwealth}

Posner (2000) suggests that the end of dueling resulted from increases in wealth that were able to fund better mechanisms for settling disputes: "So when states finally gain a sufficient amount of wealth and power, they replace the forms of nonlegal regulation [dueling] with more purely legal institutions, and eventually succeed because the legal institutions are better" (p. 218). Posner's argument is consistent with the general rise in wealth and decline of dueling through out the nineteenth century. However, it is inconsistent with the history of dueling during the English commonwealth. ${ }^{47}$

Dueling was most popular in the seventeenth century. Thomas Hoby's translation of the Italian Castiglione's The Book of the Courier in 1561 is the first English book to mention dueling among aristocrats. ${ }^{48}$ Over the next 40 years, several treatises on dueling, courtesy guides, and codes of honor

44. In his discussion of Missouri duels, Steward (2000) contrasts the differences in social status between the old South and Missouri. The old South had a formal class structure, whereas Missouri was more egalitarian. He also notes a difference in lethality consistent with our hypothesis: "Missouri was not like the Deep South. In Dixie many duels were 'bloodless...' While southern duels often left both reputation and body undamaged, Missourians sought satisfaction with blood" (p. 8).

45. Hughes (1998) reports that the fatality rate for Italian duels in the late nineteenth century actually fell to $0.5 \%$ (p. 73).

46. In most of the American duels discussed by Baldick (1965), the outcomes were fatal.

47. The dueling screen model is also consistent with the fall of dueling.

48. Castiglione (1967). 
were published in England, and there was a concomitant increase in the amount of dueling. Peltonen (2001) reports that "the numbers of duels and challenges mentioned in newsletters and correspondence jumped from five in the 1580 s to nearly twenty in the 1590 s. The peak was reached in the 1610 s with thirty-three recorded duels and challenges, although the number of actual duels and challenges must have been much higher" (pp. 9-10).

In contrast, there was a dearth of dueling in England from 1642 to 1660, the years of the Civil War and Commonwealth: "After thriving during the first decades of the seventeenth century, duelling became an extremely rare occurrence in the Civil War. ... The same conditions obtained during the Protectorate. ... After the Restoration, duelling very naturally regained all its previous prestige, and soon ballrooms, coffee-houses and public walks were all scenes of fighting and bloodshed" (Baldick, 1965, pp. 9-10). ${ }^{49}$

During the nonrepublican years the government of the monarchs ruled much as they had in times past, through the use of patronage. It was the perogative of the royal court to deliver positions within the administration, military, and general government to whom it pleased, and, as discussed earlier, these ministers would then act as patrons to lesser individuals for other positions in the civil service. However, the Civil War and the subsequent government of Oliver Cromwell was considerably different. Aylmer (1973) states, "The coming of the Protectorate and the institutional changes which followed it altered the pattern of appointments appreciably. Direct appointment by Parliament virtually disappeared" (p. 70).

It would be an error to suggest Cromwell, who enjoyed virtually supreme power and had complete control in appointing great officers of state, dispensed with a system of patronage, but just as incorrect to suggest that the system of appointment and promotion remained the same. At a fundamental level, the civil wars and the subsequent governments were driven by serious divisions of theology, and at one level Cromwell chose appointments by using a "religious screen." At a personal level Cromwell was concerned with what he termed "the root of the matter," which most historians seem to take as a minimum standard of Puritan belief.

49. Kiernan (1988) also confirms this: "In England [dueling] fell off after 1642 when the civil wars broke out, but in the Royalist camp steps had to be taken to curb it" (p. 94). 
Consistent with this was the purging of many administrative positions, based on belief. ${ }^{50}$ Cromwell also put an emphasis on merit and ability that was absent in the royal administrations before and after the Commonwealth:

The Commonwealth was a revolutionary regime. It had come to power through civil war and military force, and its legality was not universally recognised in the country. This put a premium on political or ideological reliability, and meant that loyalty to the government was something which patrons needed to stress, and appointing bodies to satisfy themselves about. It also led to a formidable battery of tests and oaths... Over and above loyalty and morality, we find emphasis on men's actual fitness for the work in question. It could mean a particular skill in writing, accounting or foreign languages, or a more all-round ability. (Aylmer, 1973, pp. 61-62, emphasis added)

Dueling appears to have owed its existence not to the level of wealth, but to the presence of patronage and its requirement for screening. ${ }^{51}$

50. There was the "Plundered Minister's Committee" which was "responsible for purging non-puritan Episcopalian clergymen and imposing tests on all others; these were often replaced by previously 'plundered' puritan ministers" (Aylmer, 1973, p. 10). Cromwell also introduced the "Ejection Commissioners" to get rid of ministers for "misconduct or non-subscription to the prescribed minimum of Protestant belief." (Aylmer, 1973, p. 61).

51. China provides another case in which there was an absence of patronage and dueling. Beginning as early as the third century B.C. and ending in 1905, China introduced a series of imperial examinations for the civil service: "Early imperial China is nevertheless famous, and deservedly so, for instituting and systematizing rational, merit-oriented techniques for the recruitment, placement, and evaluation of government officials that had no counterparts elsewhere until very recent times" (Hucker, 1978, p. 156). Hucker continues: "Once appointed to an office, a man served on probation for a year; if he performed satisfactorily, the appointment was then made permanent. Every third year officials submitted efficiency ratings on their subordinates, which led to salary adjustments and occasionally to promotions, demotions, or dismissals" (p. 159). These exams were conducted as a series of tournaments. Exams would be held over several weeks each year in small country towns, with the very best students moving on to provincial capitals and then to the royal court. Once they were eligible and appointed on the bases of merit, performance was monitored on the job. Consistent with our model, in this system of merit-based civil service, dueling did not exist, because its screening function was not required. 


\subsection{Dueling's Decline in the Late Nineteenth Century}

Our final piece of evidence that dueling existed because of patronage in the senior civil service is the decline of dueling throughout the nineteenth century. For England, the eighteenth century saw tremendous growth in its Empire. By end of this century, the colonies of British North America and India were not controlled by monopoly companies, but rather were being administered by the British civil service. This change was part of an enormous growth in the civil service. In 1700 there may have been 1,000 to 2,000 members, whereas by 1914 the British Civil Service had 167,628 employees, and by 1919 this figure had grown to 393,205 (Campbell, 1965, p. 56). ${ }^{52}$ These positions were not filled by patronage but through examinations and interviews with selection boards. France, Germany, and other European countries obtained colonial empires in the nineteenth century with similar civil administrations, again appointed generally outside the realm of patronage.

Likewise in the U.S., the nineteenth century saw a decline in the role of patronage, culminating in the Pendleton Act of 1883. Johnson and Libecap (1994) document how the increase in the sheer size of the civil service over this period prevented the president or members of Congress from controlling and benefiting from their patronage appointments. In noting that the federal work force grew from 26,000 to 51,000 between 1851 and 1871, they write as follows: "When the labor force was small, federal politicians could monitor the actions of their appointees to guarantee their allegiance and to see that they responded to the demands of influential constituents... As the federal labor force grew, however, careful supervision of patronage workers by the President or members of Congress, as had been practiced earlier, became more difficult" (pp. 97-98).

Other changes were taking place between 1780 and 1850 that also led to the radical reforms in civil administration. The industrial revolution, changes in communication technology, and tremendous falls in transportation costs all led to a significant increase in the size and wealth of the middle class. This increase in wealth outside the aristocratic group

52. Brewer (1990) states that in the seventeenth century "the overall picture is clear: the central administrative apparatus was tiny" (p. 65). He estimates that in 1688 the civil service employment was 2,500 men. By 1760 he estimates it had grown to 16,000 . 
increased the gains from trade outside the aristocracy and lowered the attractiveness of social capital as a method for policing exchanges in the elite group.

Regardless of the reasons, whether from increased size of bureaucracy, better gains from outside the group, or lower-cost methods of measuring merit, there is no denying that formal patronage was replaced by a professional bureaucracy in the first half of the nineteenth century. As merit replaces patronage, dueling ceases to play a screening role. Not surprisingly, then, the changes in size of governments in Europe and the U.S. coincided with the end of dueling and a general fall in lethal duels. In England the duel all but ceased to exist by 1850. In France and Germany the duel remained until World War I, but the probability of death diminished greatly. In Germany sword duels ceased using the épée and switched to the saber. This weapon was curved to prevent penetration, the tip was often dulled, and the blade was rinsed with an antiseptic carbolic acid solution to prevent infection (McAleer, 1994, p. 62). Most German duels, however, were with pistols, and, as has already been mentioned, the dueling rules essentially guaranteed a low fatality rate. As for the French duel of the late nineteenth century, the chance of death had become something of a joke in other parts of Europe: "The Germans did indeed regard dueling in the Third Republic as something of a joke because of its hilariously low fatality rate, which, from a pool of between four and five hundred duels a year until the first decade of the twentieth century, never exceeded twelve annual deaths and was often as low as two per year" (McAleer, 1994, p. 75). Although his estimates on the number of duels is different, Nye (1998) suggests similar chances of survival: "[B]etween 1875 and 1900 there were at least two hundred duels each year, perhaps three hundred in certain years, and in periods of unusual political effervescence. ... dozens of duels a week for weeks on end... Fatalities were rare. ... there were probably no more than two dozen deaths in duels in this era" (p. 88). Contrast this with French dueling at the turn of the seventeenth century, where "the cream of the French nobility - perhaps ten thousand men-perished in duels in the last decade of the sixteenth and first decade of the seventeenth centuries" (Nye, 1998 , p. 83). Indeed, it has been estimated that over the first half of the seventeenth century between 300 and 500 noblemen died from duels per 
year (McAleer, 1994, p. 18). By World War I, dueling was little more than fencing with the possibility of scarring due to limited face protection. ${ }^{53}$ Dueling had ceased to be used as a screen for social capital.

\section{Conclusion}

The nineteenth century was a transition century. One may well be amazed at the number of institutions that developed centuries earlier and were either seriously transformed or terminated during this time. Patronage and purchase of military and civil offices, along with dueling, are just a few examples. Viewed from the twenty first century, many of these institutions seem archaic and beyond economic rationale. Yet, if we seriously believe institutions are formed for the purpose of maximizing wealth net of transaction costs, then understanding these costs should provide an explanation of these rules. We take as given that civil servants were appointed through a system of patronage in a world where direct monitoring of service and appointment, and promotion based on merit, seldom existed. We view dueling as a response to the problem of selecting who would be eligible for such positions of power. Our model implies a participation constraint to duel, whereby participation in dueling indicated a sufficient investment in social capital had been made. This investment policed behavior in self-enforced political transactions. Our hypothesis not only provides an efficiency rationale for dueling, but it also explains many of its puzzling features. Dueling was neither a recreational sport, nor an irrepressible manifestation of masculine aggression, nor a poor substitute for law courts. The purpose of dueling was to screen for individuals who would behave properly in their post and not threaten the position of their patron.

\section{References}

Allen, Douglas W. 1998. "Compatible Incentives and the Purchase of Military Commissions,” 27 Journal of Legal Studies January 45-66.

53. "By the end of the nineteenth century, the ritual had become overly refined and excessively formalized, indicating a shrinking, a withdrawal. The self-conscious obsession with technique and protocol was a symptom of decadence" (McAleer, 1994, p. 45). Hughes (1998) reports that dueling fatalities also fell in Italy over the last part of the nineteenth century. Of 3,918 duels reported between 1879 and 1899 in Italy, only 20 deaths resulted. Italians in this period also fought with sabers (p. 73). 
2002. "The British Navy Rules: Monitoring and Incompatible Incentives in the Age of Fighting Sail," 39 Explorations in Economic History 204-31.

_ 2005. "Purchase, Patronage, and Professions: Incentives and the Evolution of Public Office in Pre-Modern Britain," 161(1) Journal of Institutional and Theoretical Economics 57-79.

Aylmer, Gerald E. 1961. The King's Servants: The Civil Service of Charles I. London: Routledge and Kegan Paul.

- 1973. The State's Servants: The Civil Service of the English Republic 16491660. London: Routledge and Kegan Paul.

Baldick, Robert. 1965. The Duel: A History of Duelling. New York: Clarkson Potter.

Berman, Eli. 2000. "Sect, Subsidy and Sacrifice: An Economist's View of UltraOrthodox Jews," 115(3) Quarterly Journal of Economics 905-53.

Billacois, François. 1990. The Duel: Its Rise and Fall in Early Modern France. New Haven, CT: Yale University Press.

Boswell, James. 1980. Life of Johnson. Oxford: Oxford University Press.

Brewer, John. 1990. The Sinews of Power: War, Money and the English State, 1699 1783. Cambridge, MA: Harvard University Press.

Camerer, Colin. 1988. "Gifts as Economic Signals and Social Symbols," 94 American Journal of Sociology S180-S214.

Campbell, George A. 1965. The Civil Service in Britain. London: Duckworth.

Carmichael, H. Lorne, and W. Bentley MacLeod. 1997. "Gift Giving and the Evolution of Cooperation," 38(3) International Economic Review 485-509.

Castiglione, Baldassarre. 1967. The Book of Courtier from the Italian, done into English by Sir Thomas Hoby, anno 1561, with an Introduction by Sir Walter Raleigh. New York: AMS Press.

Cochran, Hamilton. 1963. Noted American Duels and Hostile Encounters. New York: Chilton Books.

Coleman, James. 1988. "Social Capital in the Creation of Human Capital," 94 American Journal of Sociology S95-S120.

Dasgupta, Partha, and Ismail Serageldin, eds. Social Capital: A Multifaceted Perspective. Washington, D.C.: World Bank.

François, Patrick. 2002. Social Capital and Economic Development. New York: Routledge.

Freeman, Joanne B. 2001. Affairs of Honor: National Politics in the New Republic. New Haven, CT: Yale University Press.

Frevert, Ute. 1998. "The Taming of the Noble Ruffian: Male Violence and Dueling in Early Modern and Modern Germany," in Peter Spierenburg, ed., Men and Violence: Gender, Honor, and Rituals in Modern Europe and America. Columbus, $\mathrm{OH}$ : Ohio State University Press.

Greif, Avner. 1989. "Reputation and Coalitions in Medieval Trade: Evidence on the Maghribi Traders," 49 Journal of Economic History 857-82. 
- 1993. "Contract Enforceability and Economic Institutions in Early Trade: The Maghribi Traders' Coalition," 83 American Economic Review 525-48.

Halliday, Hugh. 1999. Murder Among Gentlemen: A History of Duelling in Canada. Toronto: Robin Brass.

Hucker, Charles O. 1978. China to 1850: A Short History. Stanford, CA: Stanford University Press.

Hughes, Steven. 1998. "Men of Steel: Dueling, Honor, and Politics in Liberal Italy," in Pieter Spierenburg, ed., Men and Violence: Gender, Honor, and Rituals in Modern Europe and America. Columbus, OH: Ohio State University Press.

Iannaccone, Laurence. 1992. "Sacrifice and Stigma: Reducing Free-Riding in Cults, Communes, and Other Collectives," 100(2) Journal of Political Economy 271-91.

Johnson, Ronald and Gary Libecap. 1994. "Patronage to Merit and Control of the Federal Government Labor Force," 31 Explorations in Economic History 91-119.

Kiernan, Victor G. 1988. The Duel in European History: Honour and the Reign of Aristocracy. Oxford: Oxford University Press.

Klein, Benjamin, and Keith Leffler. 1981. "The Role of Market Forces in Ensuring Contractual Performance," 89 Journal of Political Economy 615-41.

Kline, Mary Jo. 1973. Alexander Hamilton: A Biography in His Own Words. New York: Harper and Row.

Kline, Lessig Lawerance, 1995. "The Regulation of Social Meaning," 62 The University of Chicago Law Review 943-1045.

McAleer, Kevin. 1994. Dueling: The Cult of Honor in Fin-de-Siecle Germany. Princeton, NJ: Princeton University Press.

Milgrom, Paul, Douglass North, and Barry Weingast. 1990. "The Role of Institutions in the Revival of Trade: The Law Merchant, Private Judges, and the Champagne Fairs," 2(1) Economics and Politics 1-23.

Morris, Terrance A. 1999. Tudor Government. New York: Routledge.

Murray, Ellen N. 1984. The Code of Honor: Dueling in America: American Dueling Pistols and Related Ephemera from the Collection of Lt. Col. and Mrs. William R. Orbelo. Washington, TX: Star of the Republic Museum.

Nye, Robert. 1998. "The End of the Modern French Duel," in Pieter Spierenburg, ed., Men and Violence: Gender, Honor, and Rituals in Modern Europe and America. Columbus, OH: Ohio State University Press.

Parker, David. 2001. "Law, Honor, and Impunity in Spanish America: The Debate over Dueling, 1870-1920,” 19 (Summer) Law and History Review 311-42.

Peltonen, Markku. 2001. Francis Bacon, The Earl of Northampton, and the Jacobean Anti-duelling Campaign. 44(1) The Historical Journal 1-28.

Pepys, Samuel. 1970. The Diary of Samuel Pepys, Vol. 8. R. Latham and W. Matthews, eds., Berkeley: University of California Press.

Plumb, John H. 1963. England in the Eighteenth Century. New York: Penguin. 
Posner, Eric. 1996. "Law, Economics, and Inefficient Norms," 144 University of Pennsylvania Law Review 1697-744. 2000. Law and Social Norms. Cambridge, Harvard University Press.

Schwartz, Warren, Keith Baxter, and David Ryan. 1984. "The Duel: Can These Gentlemen Be Acting Efficiently?" 13 Journal of Legal Studies 321-53.

Steward, Dick. 2000. Duels and the Roots of Violence in Missouri. Columbia: University of Missouri Press.

Wells, Harwell. 2001. "The End of the Affair? Anti-Dueling Laws and Social Norms in Antebellum America," 54 Vanderbilt Law Review 1805-47. 